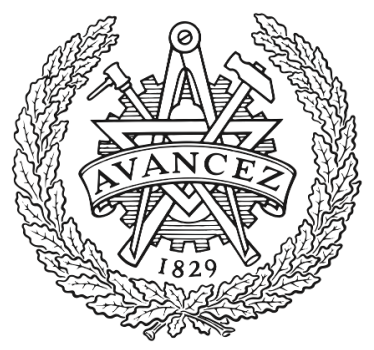

CHALMERS

UNIVERSITY OF TECHNOLOGY

\title{
First-Principles Study of Order-Disorder Transitions in Pseudobinary Clathrates
}

Downloaded from: https://research.chalmers.se, 2023-04-26 15:26 UTC

Citation for the original published paper (version of record):

Brorsson, J., Palmqvist, A., Erhart, P. (2021). First-Principles Study of Order-Disorder Transitions in Pseudobinary Clathrates. Journal of Physical Chemistry C, 125(41): 22817-22826.

http://dx.doi.org/10.1021/acs.jpcc.1c06638

N.B. When citing this work, cite the original published paper. 


\title{
First-Principles Study of Order-Disorder Transitions in Pseudobinary Clathrates
}

\author{
Joakim Brorsson, Anders E. C. Palmqvist, and Paul Erhart*
}

Cite This: J. Phys. Chem. C 2021, 125, 22817-22826

Read Online

ABSTRACT: It has been recently demonstrated that the pseudoternary $\mathrm{Ba}_{8} \mathrm{Al}_{x} \mathrm{Ga}_{y} \mathrm{Ge}_{46-x-y}$ clathrate undergoes an order-disorder transition with increasing temperature that can be observed via site occupation factors (SOFs) and manifests itself, e.g., in electrical transport properties. Here, we generalize this result and analyze the characteristics of this order-disorder transition in the pseudobinary clathrates $\mathrm{Ba}_{8} \mathrm{Ga}_{x} \mathrm{Ge}_{46-x}, \mathrm{Ba}_{8} \mathrm{Ga}_{x} \mathrm{Si}_{46-x}$, $\mathrm{Ba}_{8} \mathrm{Al}_{x} \mathrm{Ge}_{46-x}$, and $\mathrm{Ba}_{8} \mathrm{Al}_{x} \mathrm{Si}_{46-x}$. To this end, we employ atomistic simulations that combine alloy cluster expansions trained against density functional theory calculations with Wang-Landau and ensemble Monte Carlo simulations. The simulations show that all four systems studied here display order-disorder transitions for at least some composition range. Based on an extensive literature survey, we also provide evidence for signatures of the transition in earlier experimental studies that to the best of our knowledge

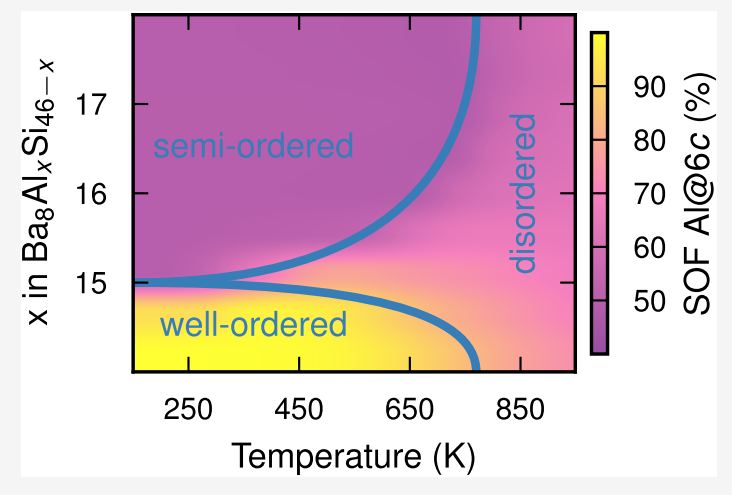
have hitherto not been related to such transitions. The predicted transition temperatures are lower for $\mathrm{Ba}_{8} \mathrm{Ga}_{x} \mathrm{Ge}_{46-x}$ and $\mathrm{Ba}_{8} \mathrm{Ga}_{x} \mathrm{Si}_{46-x}$ than for $\mathrm{Ba}_{8} \mathrm{Al}_{x} \mathrm{Ge}_{46-x}$ and $\mathrm{Ba}_{8} \mathrm{Al}_{x} \mathrm{Si}_{46-x}$, although it appears that the simulations underestimate the transition temperatures for Ga-containing systems compared to the experiment. This nonetheless provides a sensible explanation for why the experimentally determined Al SOFs agree better with the simulated high-temperature disordered configurations, while the Ga SOFs more closely agree with the simulated ground-state configurations. As a result of stronger interactions, the SOFs vary substantially, especially near the stoichiometric 16:30 composition, providing an indication of why it has proved difficult to synthesize $\mathrm{Ba}_{8} \mathrm{Al}_{x} \mathrm{Ge}_{46-x}$ and $\mathrm{Ba}_{8} \mathrm{Al}_{x} \mathrm{Si}_{46-x}$ samples at this ratio. The present study thereby yields detailed atomic-scale insights into the ordering in inorganic clathrates that, given the connection to transport properties established earlier, are not only useful from a fundamental perspective but also relevant for applications.

\section{INTRODUCTION}

In recent years, the importance of order-disorder transitions in functional materials has received increased attention. Such transformations have not only been observed in a wide variety of different materials, which either contain vacancies or exhibit mixed occupancies, but also been shown to profoundly influence physical properties, e.g., in pnictides, ${ }^{1-4}$ oxides, ${ }^{5}$ chalcogenides, ${ }^{6-13}$ half-Heuslers, ${ }^{14,15}$ skutterudites, ${ }^{16}$ and vacancy-containing clathrates. ${ }^{17,18}$ Moreover, it has been recently established that order-disorder transitions in the inorganic clathrate $\mathrm{Ba}_{8} \mathrm{Al}_{x} \mathrm{Ga}_{y} \mathrm{Ge}_{46-x-y}$ have a notable impact on the electrical transport properties. ${ }^{19}$ This group of materials has been extensively studied because of their comparatively good thermoelectric properties and their fascinating structural motifs, which can be described as an interwoven network of host and guest lattices. Even so, a complete understanding of the relationship between the unique crystal structure and the diverse and interesting properties is still lacking. ${ }^{20-22}$ It is therefore interesting to determine if order-disorder transitions are a general feature in clathrates and how the characteristics of such transitions depend on chemistry and temperature. Here, we specifically focus on type-I clathrates, which possess $\mathrm{P} m \overline{3} n$
(International Tables of Crystallography number 223) symmetry with the chemical formula $\mathrm{A}_{8} \mathrm{~B}_{x} \mathrm{C}_{46-x}$. The host atoms $(\mathrm{B} / \mathrm{C})$ are distributed between $6 c, 16 i$, and $24 k$ Wyckoff sites, forming a framework that includes small dodecahedral and larger tetrakaidecahedral cages, which enclose the guest atoms (A) located at the $2 a$ and $6 d$ positions, respectively (Figure 1a). Typically, the guest species are alkali or alkaline earth metals, while the host species belong to groups 13 and 14 of the periodic table. ${ }^{21,22}$

Until recently, the existence of transitions between ordered and disordered states has only been established for the vacancy-containing clathrates $\mathrm{Rb}_{8} \mathrm{Sn}_{44} \square_{2}$ and $\mathrm{Cs}_{8} \mathrm{Sn}_{44} \square_{2}$, ${ }^{17,18}$ which take place at around 353 and $363 \mathrm{~K}$, respectively. Yet, there are several additional examples of thermodynamic or

Received: July 26, 2021

Revised: September 27, 2021

Published: October 12, 2021 

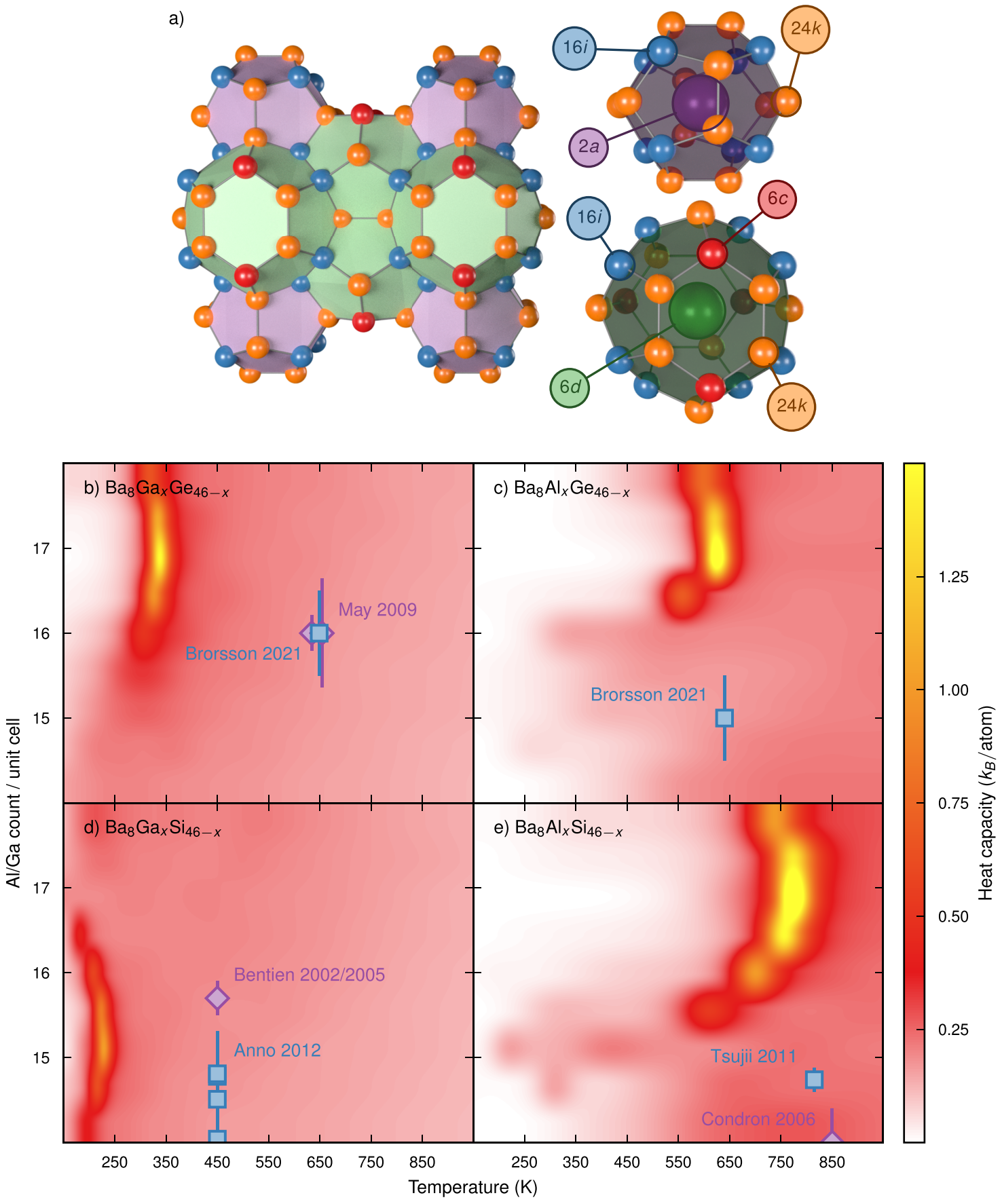

Figure 1. Illustration of a representative type-I clathrate structure (a) as well as heat maps $(\mathrm{b}-\mathrm{e})$ showing the temperature and composition dependence of the contribution to heat capacity from the disorder for $\mathrm{Ba}_{8} \mathrm{Ga}_{x} \mathrm{Ge}_{46-x}(\mathrm{~b}), \mathrm{Ba}_{8} \mathrm{Al}_{x} \mathrm{Ge}_{46-x}(\mathrm{c}), \mathrm{Ba}_{8} \mathrm{Ga}_{x} \mathrm{Si}_{46-x}(\mathrm{~d})$, and $\mathrm{Ba}_{8} \mathrm{Al}_{x} \mathrm{Si}_{46-x}$ (e). Experimental transition temperatures that have been extracted from ref 28 (purple diamonds in $\mathrm{b}$ ), ref 19 (blue square in $\mathrm{b}$ and $\mathrm{c}$ ), refs 32 , 33 (purple diamond in d), ref 34 (blue squares in d), ref 30 (purple diamond in e), and ref 31 (blue square in e) are also indicated. If no error bars for the compositions were stated in the original publications, we estimated them to be 0.5 atoms per unit cell, similar to other data from energydispersive X-ray spectroscopy.

structural features in the literature, which may be a direct or indirect consequence of such transitions. While some of the peculiarities in high-temperature property measurements for $\mathrm{Ba}_{8} \mathrm{Ga}_{16} \mathrm{Ge}_{30}{ }^{23-28}$ can be related to the recent discovery that this compound exhibits very slow decomposition under such conditions, $^{29}$ the fact that some appear to be reversible ${ }^{24}$ suggests that this is not a universal explanation.

The most direct evidence for a phase transition related to chemical ordering has been provided by May et al. ${ }^{28}$ who reported anomalies in both the thermal and electronic transport properties as well as a distinctive jump in the heat capacity at around $650 \mathrm{~K}$ for $\mathrm{Ba}_{8} \mathrm{Ga}_{x} \mathrm{Ge}_{46-x}$. This result is, however, by no means exclusive. Since our previous experimental and computational studies of the $\mathrm{Ba}_{8} \mathrm{Al}_{x} \mathrm{Ga}_{y} \mathrm{Ge}_{46-x-y}$ system ${ }^{19}$ included differential scanning calorimetry (DSC) experiments on the pseudobinaries $\mathrm{Ba}_{8} \mathrm{Ga}_{16} \mathrm{Ge}_{30}$ and $\mathrm{Ba}_{8} \mathrm{Al}_{16} \mathrm{Ge}_{30}$ as well as $\mathrm{Ba}_{8} \mathrm{Al}_{5} \mathrm{Ga}_{11} \mathrm{Ge}_{30}$, we were able to conclude that both of these compounds undergo a 

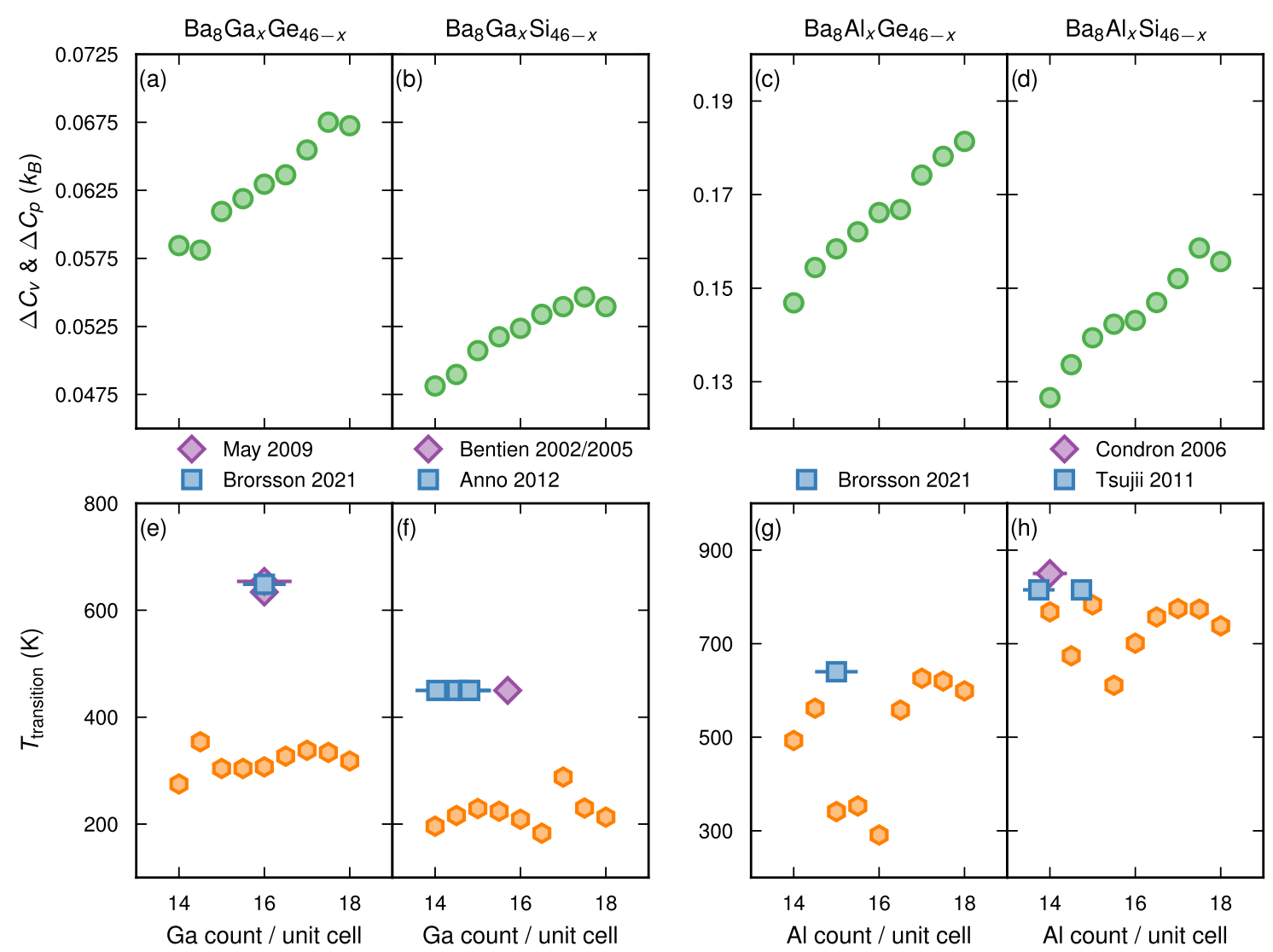

Figure 2. Composition $(x)$ dependence of the jump in the heat capacity $(\mathrm{a}-\mathrm{d})$ and the transition temperature $(\mathrm{e}-\mathrm{h})$ for $\mathrm{Ba}_{8} \mathrm{Ga}_{x} \mathrm{Ge}_{46-x}(\mathrm{a}, \mathrm{e})$, $\mathrm{Ba}_{8} \mathrm{Ga}_{x} \mathrm{Si}_{46-x}$ (b, f), $\mathrm{Ba}_{8} \mathrm{Al}_{x} \mathrm{Ge}_{46-x}$ (c, g), and $\mathrm{Ba}_{8} \mathrm{Al}_{x} \mathrm{Si}_{46-x}$ (d, h). Panels (e-h) also include data that have been extracted from ref 28 (purple diamonds in e), ref 19 (blue square in e, g), refs 32, 33 (purple diamond in f), ref 34 (blue squares in $\mathrm{f}$ ), ref 30 (purple diamond in $\mathrm{h}$ ), and ref 31 (blue squares in $\mathrm{h}$ ). In cases where standard deviations have not been explicitly stated, these have been estimated to be 0.5 atoms per unit cell, similar to other data from energy-dispersive X-ray spectroscopy.

transition at about $650 \mathrm{~K}$, in agreement with the observations by May et al. In the case of $\mathrm{Ba}_{8} \mathrm{Al}_{x} \mathrm{Si}_{46-x}$, the data published by Condron et al. ${ }^{30}$ include not only a small peak at $\sim 800 \mathrm{~K}$ in the heating curve from DSC measurements (Figure 4a in ref 30) but also a distinctive shift in thermal conductivity (Figure $5 \mathrm{c}$ in ref 30 ) at the same temperature. Crucially, corresponding features can be found in the results presented by Tsujii et al. (Figure $8 \mathrm{a}, \mathrm{c}$ in ref 31 ). There exist fewer indicators for $\mathrm{Ba}_{8} \mathrm{Ga}_{x} \mathrm{Si}_{46-x}$, yet Bentien et al. ${ }^{32}$ obtained an anomalous lattice parameter, as well as poorer refinement overall, at $450 \mathrm{~K}$ (Figure 3 in ref 32 ). While the authors were unable to relate this outlier to any systematic errors, it could be a signature of an order-disorder transition. In a previous study of the same $\mathrm{Ba}_{8} \mathrm{Ga}_{16} \mathrm{Si}_{30}$ sample, ${ }^{33}$ it was, furthermore, reported that both the disorder parameter $(\lambda)$ and the harmonic force constants $\left(\beta_{22}=\beta_{33}\right)$ for the $\mathrm{Ba}$ atom at the $6 d$ site, obtained using the maximum entropy method, were significantly higher than expected at $450 \mathrm{~K}$ (Figures 4 and 6 in ref 33). Though Anno et al. $^{34}$ have only determined the thermal conductivity for a relatively sparse set of temperatures, it is still possible to discern a shift in the slope, as well as the absolute value, at around $450 \mathrm{~K}$ (Figure 14 in ref 34) for all four of their $\mathrm{Ba}_{8} \mathrm{Ga}_{x} \mathrm{Si}_{46-x}$ samples. We found similar features in the reported property measurements for several pseudoternary clathrates, including $\mathrm{Ba}_{8-y} \mathrm{Eu}_{y} \mathrm{Al}_{x} \mathrm{Si}_{46-x}{ }^{30} \mathrm{Ba}_{8} \mathrm{Ga}_{x} \mathrm{In}_{y} \mathrm{Ge}_{46-x-y}$, $\mathrm{Ba}_{8} \mathrm{~B}_{x} \mathrm{Al}_{y} \mathrm{Si}_{46-x-y}{ }^{36}$ and $\mathrm{Ba}_{8-y} \mathrm{Sr}_{y} \mathrm{Al}_{x} \mathrm{Si}_{46-x}{ }^{37}$

Materials with complex crystal structures, such as type-I clathrates, feature a vast configurational space. Computation- ally, this principal challenge can be efficiently addressed using a combination of density functional theory (DFT) calculations, alloy CEs, and MC simulations. ${ }^{19,38-41}$ In addition to providing evidence for the existence of order-disorder transitions, ${ }^{19,41}$ these studies have, moreover, revealed the temperature and composition dependence of the chemical ordering $^{38-40}$ and established a strong correlation between site occupation factors (SOFs) and electronic transport properties. $^{19,38}$ Here, we build on these discoveries using a combination of CEs and Wang-Landau (WL) simulations to map the temperature and composition dependence of the transition for the four pseudobinary clathrates $\mathrm{Ba}_{8} \mathrm{Ga}_{x} \mathrm{Ge}_{46-x}$, $\mathrm{Ba}_{8} \mathrm{Al}_{x} \mathrm{Ge}_{46-x}, \mathrm{Ba}_{8} \mathrm{Ga}_{x} \mathrm{Si}_{46-x}$, and $\mathrm{Ba}_{8} \mathrm{Al}_{x} \mathrm{Si}_{46-x}$. We start by analyzing the contributions to the heat capacity from the disorder as a function of composition and compare the transition temperatures extracted from the calculations with data from the literature. Then, we discuss the order-disorder transition in terms of variations in the SOFs, before comparing the results with experimental data. Finally, we present an analysis of possible reasons for the deviations between the calculated and measured transition temperatures for Gacontaining systems. The CEs have been constructed and sampled using the same procedures as in our previous studies; $^{19,38,39,42}$ the computational details can be found in the Supporting Information, including summaries of the electronic structure calculations (Note S1) ${ }^{43-45}$ construction (see Note S2 and Figures S1-S3), and sampling (see Note S3 

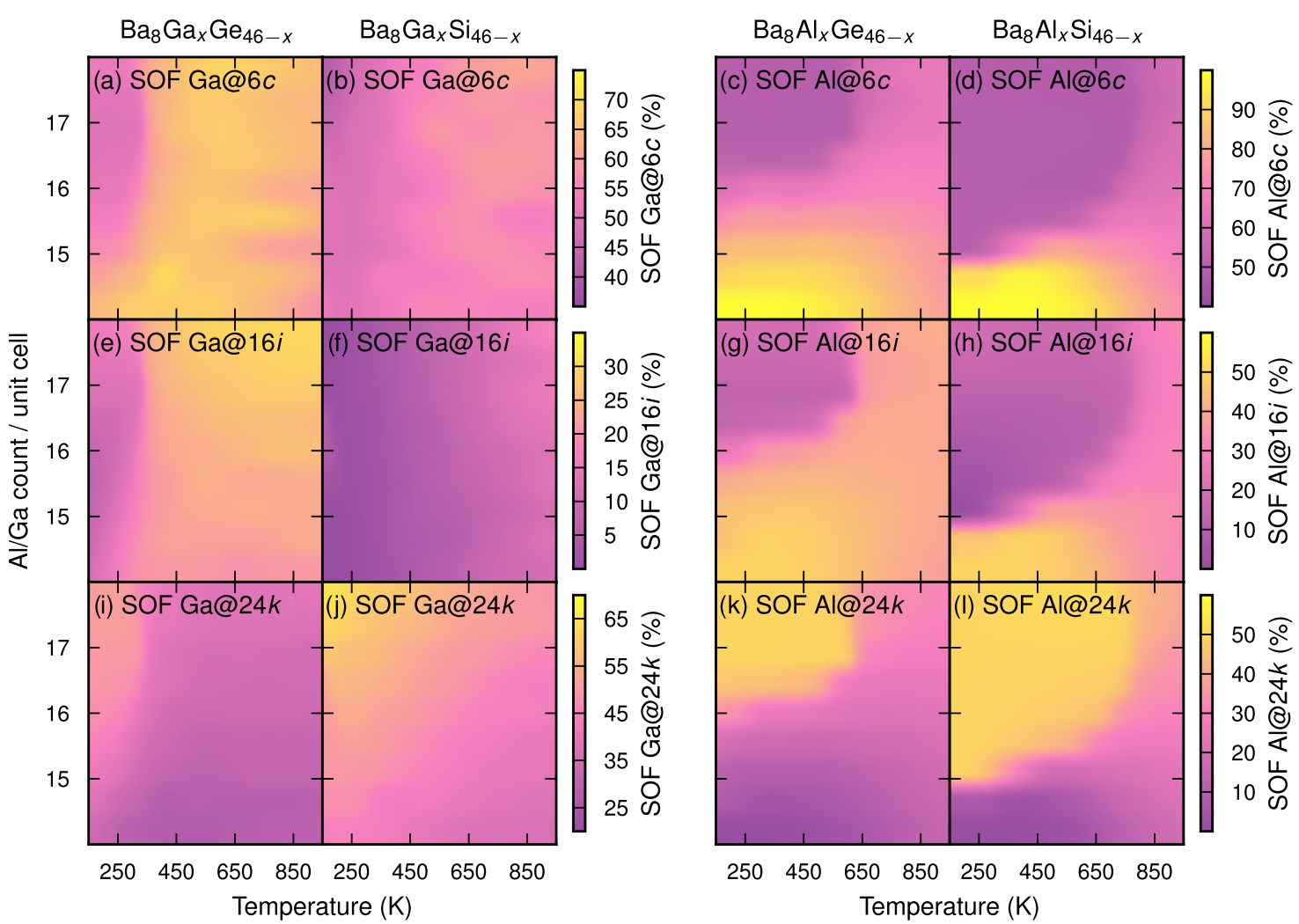

Figure 3. SOFs as functions of temperature and composition for $\mathrm{Al} / \mathrm{Ga}$ atoms on $6 c(\mathrm{a}-\mathrm{d}), 16 i(\mathrm{e}-\mathrm{h})$, and $24 k(\mathrm{i}-\mathrm{l})$ sites for $\mathrm{Ba}_{8} \mathrm{Ga}_{x} \mathrm{Ge}_{46-x}(\mathrm{a}, \mathrm{e}$, i), $\mathrm{Ba}_{8} \mathrm{Ga}_{x} \mathrm{Si}_{46-x}(\mathrm{~b}, \mathrm{f}, \mathrm{j}), \mathrm{Ba}_{8} \mathrm{Al}_{x} \mathrm{Ge}_{46-x}(\mathrm{c}, \mathrm{g}, \mathrm{k})$, and $\mathrm{Ba}_{8} \mathrm{Al}_{x} \mathrm{Si}_{46-x}$ (d, h, l).

and Figure S4) of the alloy CEs ${ }^{42,46-49}$ as well as the phononic heat capacity calculations (Note S4). ${ }^{50,51}$

\section{RESULTS AND DISCUSSION}

Features in the Heat Capacities. The contributions to the heat capacities from the disorder obtained via $\mathrm{WL}$ simulations (Figure $1 \mathrm{~b}-\mathrm{e}$ ) clearly indicate that all of the pseudobinary clathrates considered in this study $\left(\mathrm{Ba}_{8} \mathrm{Ga}_{x} \mathrm{Ge}_{46-x}, \mathrm{Ba}_{8} \mathrm{Al}_{x} \mathrm{Ge}_{46-x}, \mathrm{Ba}_{8} \mathrm{Ga}_{x} \mathrm{Si}_{46-x}\right.$, and $\mathrm{Ba}_{8} \mathrm{Al}_{x} \mathrm{Si}_{46-x}$ ) exhibit order-disorder transitions. Specifically, sharp peaks can be observed at specific temperatures, which are hallmarks of continuous phase transitions. ${ }^{52}$ Interestingly, the calculated transition temperatures are significantly lower for $\mathrm{Ba}_{8} \mathrm{Ga}_{x} \mathrm{Ge}_{46-x}$ and $\mathrm{Ba}_{8} \mathrm{Ga}_{x} \mathrm{Si}_{46-x}(200-300 \mathrm{~K})$ compared to $\mathrm{Ba}_{8} \mathrm{Al}_{x} \mathrm{Ge}_{46-x}$ and $\mathrm{Ba}_{8} \mathrm{Al}_{x} \mathrm{Si}_{46-x}(600-800 \mathrm{~K})$. Furthermore, the transition temperatures are higher for $\mathrm{Ba}_{8} \mathrm{Ga}_{x} \mathrm{Ge}_{46-x}$ than $\mathrm{Ba}_{8} \mathrm{Ga}_{x} \mathrm{Si}_{46-x}$, while the opposite behavior is observed when comparing $\mathrm{Ba}_{8} \mathrm{Al}_{x} \mathrm{Ge}_{46-x}$ and $\mathrm{Ba}_{8} \mathrm{Al}_{x} \mathrm{Si}_{46-x}$. The results clearly show that this phenomenon is sensitive to the nature of trivalent elements $(\mathrm{Al}$ and $\mathrm{Ga})$. The fact that the replacement of $\mathrm{Ge}$ with $\mathrm{Si}$ in $\mathrm{Ba}_{8} \mathrm{Ga}_{x} \mathrm{Ge}_{46-x}$ and $\mathrm{Ba}_{8} \mathrm{Al}_{x} \mathrm{Ge}_{46-x}$ yields different effects could be explained in terms of lattice strain since the $\mathrm{Al}$ and $\mathrm{Si}$ atoms have smaller atomic radii than $\mathrm{Ga}$ and Ge. It is furthermore shown that the transition temperature is not fixed for a given system but rather varies slightly with composition, which is the most salient for $\mathrm{Ba}_{8} \mathrm{Al}_{x} \mathrm{Si}_{46-x}$, followed by $\mathrm{Ba}_{8} \mathrm{Al}_{x} \mathrm{Ge}_{46-x}, \mathrm{Ba}_{8} \mathrm{Ga}_{x} \mathrm{Si}_{46-x}$, and $\mathrm{Ba}_{8} \mathrm{Ga}_{x} \mathrm{Ge}_{46-x}$. When compared to experimental data extracted from the literature (as outlined in the Introduction), it is clear that a relatively good agreement is achieved for $\mathrm{Ba}_{8} \mathrm{Al}_{x} \mathrm{Ge}_{46-x}$ and $\mathrm{Ba}_{8} \mathrm{Al}_{x} \mathrm{Si}_{46-x}$, while a significant underestimation by $\sim 200-300 \mathrm{~K}$ is observed in the case of $\mathrm{Ba}_{8} \mathrm{Ga}_{x} \mathrm{Ge}_{46-x}$ and
$\mathrm{Ba}_{8} \mathrm{Ga}_{x} \mathrm{Si}_{46-x}$. Though we have performed various tests for the purpose of identifying the cause of these discrepancies, which are presented in the Analysis of Deviations section, we have not found an entirely satisfactory explanation.

To further characterize the transformation, we have extracted and compared the transition temperatures together with the magnitude of the associated jumps in the heat capacity (Figure 2). While the data clearly show that the latter increase almost linearly with the amount of the trivalent element $(x)$, similarly to the case of $\mathrm{Ba}_{8} \mathrm{Al}_{x} \mathrm{Ga}_{16-x} \mathrm{Ge}_{30}{ }^{19}$ the former do not exhibit a clear composition dependence. This can be due to the fact that the identification of the transition temperature is ambiguous, especially for cases where the heat capacity does not exhibit a clear peak. It thus appears as if the correlation between the transition temperature and the magnitude of the jump is relatively weak. Interestingly, we observed clear linear trends for both these quantities in our previous study of $\mathrm{Ba}_{8} \mathrm{Al}_{x} \mathrm{Ga}_{16-x} \mathrm{Ge}_{30}{ }^{19}$ For such a pseudoternary system, however, the number of trivalent elements remains constant when $x$ increases, which is not true for a pseudobinary, such as $\mathrm{Ba}_{8} \mathrm{Ga}_{x} \mathrm{Ge}_{46-x}$. The fact that bonds between trivalent elements, which are known to be unfavorable, ${ }^{20,39}$ are more numerous in the disordered state suggests that the difference in energy between the ground and high-temperature states should grow with the $\mathrm{Al} / \mathrm{Ga}$ content. At the same time, however, the total number of possible configurations increases, which, in turn, leads to a higher entropy for the disordered state. Indeed, the linear temperature dependence of the heat capacity jump, for all four clathrates, can be seen as an indication that the entropic contributions actually dominate (Figure 2). 


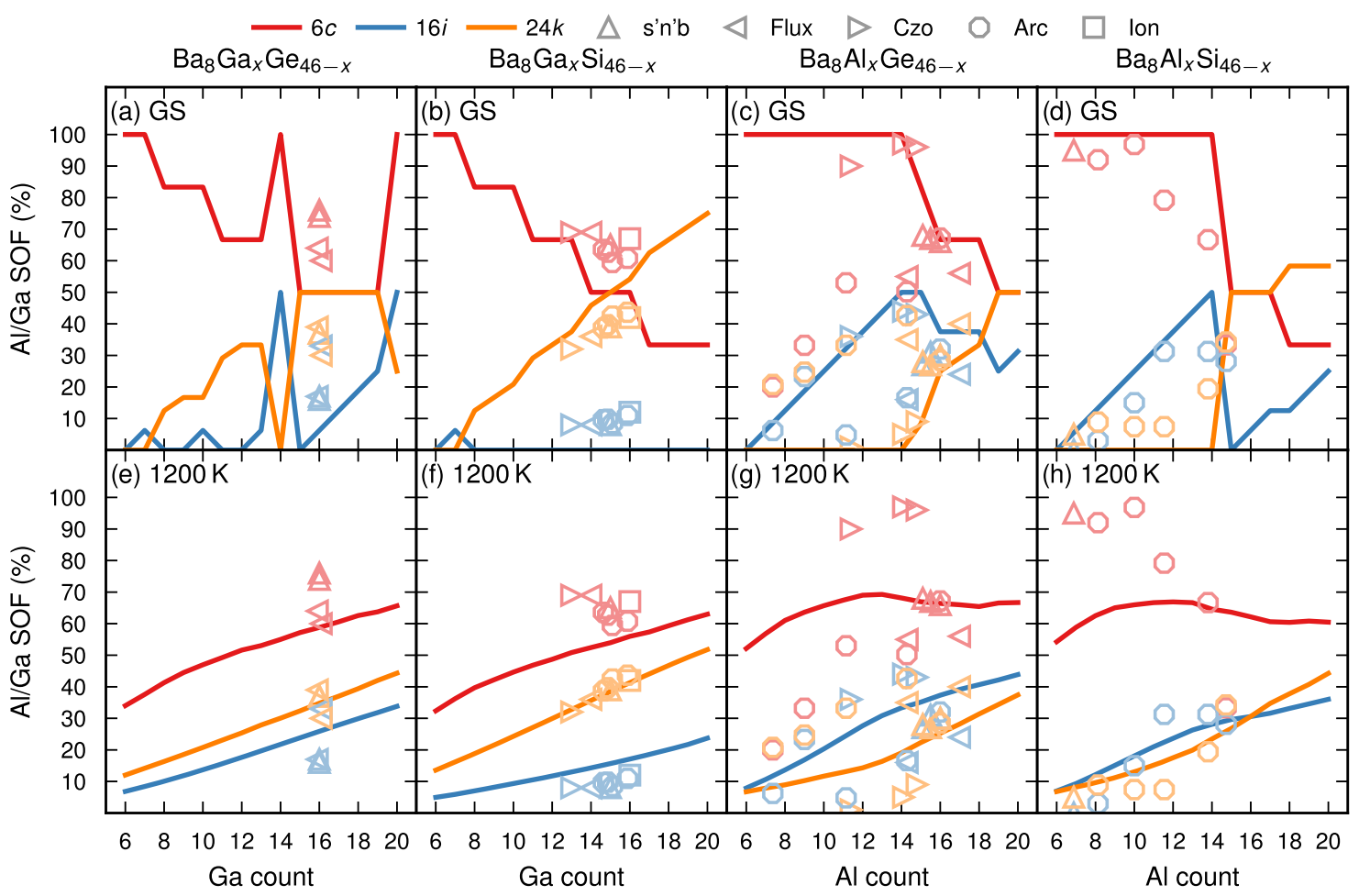

Figure 4. $\mathrm{Al} / \mathrm{Ga}$ SOFs of $6 c$ (red), $16 i$ (blue), and $24 k$ (orange) sites as functions of temperature for ground (a-d) and high-temperature (e-h) $\mathrm{Ba}_{8} \mathrm{Ga}_{x} \mathrm{Ge}_{46-x}$ (a, e), $\mathrm{Ba}_{8} \mathrm{Ga}_{x} \mathrm{Si}_{46-x}(\mathrm{~b}, \mathrm{f}), \mathrm{Ba}_{8} \mathrm{Al}_{x} \mathrm{Ge}_{46-x}(\mathrm{c}, \mathrm{g})$, and $\mathrm{Ba}_{8} \mathrm{Al}_{x} \mathrm{Si}_{46-x}$ (d, h) states. Experimental data for samples synthesized via solidstate synthesis, also referred to as "shake and bake", (upward triangles), ${ }^{53,60-64}$ flux growth ${ }^{19,32,33,53,60,62}$ (left triangle), Czochralski pulling ${ }^{19,53,62,65}$ (right triangle), arc melting ${ }^{58,66}$ (octagon), and Ar ion melting, ${ }^{67}$ (square) have also been included.

By contrast, a pairwise comparison between the different systems clearly shows that there is some degree of correlation between the transition temperature and the magnitude of the jump in the heat capacity since both quantities are significantly higher for $\mathrm{Ba}_{8} \mathrm{Ga}_{x} \mathrm{Ge}_{46-x}\left(\mathrm{Ba}_{8} \mathrm{Ga}_{x} \mathrm{Si}_{46-x}\right)$ compared to $\mathrm{Ba}_{8} \mathrm{Al}_{x} \mathrm{Ge}_{46-x}\left(\mathrm{Ba}_{8} \mathrm{Al}_{x} \mathrm{Si}_{46-x}\right)$.

Correlations with Site Occupancy Factors. In accordance with our previous MC study of the pseudobinary clathrates $\mathrm{Ba}_{8} \mathrm{Ga}_{x} \mathrm{Ge}_{46-x}, \mathrm{Ba}_{8} \mathrm{Ga}_{x} \mathrm{Si}_{46-x}, \mathrm{Ba}_{8} \mathrm{Al}_{x} \mathrm{Ge}_{46-x}$, and $\mathrm{Ba}_{8} \mathrm{Al}_{x} \mathrm{Si}_{46-x}$, 39 the WL simulations clearly demonstrate that the degree of chemical ordering, as represented by the SOFs, varies strongly with both composition and temperature (Figure 3). A comparison of the SOFs with the contributions to the heat capacities (Figure $1 \mathrm{~b}-\mathrm{e}$ ) reveals neither clear correlations nor striking differences between the systems. Yet, a common trend is that the occupation of the $6 c$ and $16 i$ sites increases (decreases) with temperature (number of $\mathrm{Al} / \mathrm{Ga}$ atoms). Just like the heat capacities, there are similarities between those systems that contain the same trivalent element. Specifically, the variations appear to be much weaker for $\mathrm{Ba}_{8} \mathrm{Ga}_{x} \mathrm{Ge}_{46-x}$ and $\mathrm{Ba}_{8} \mathrm{Ga}_{x} \mathrm{Si}_{46-x}$ relative to $\mathrm{Ba}_{8} \mathrm{Al}_{x} \mathrm{Ge}_{46-x}$ and $\mathrm{Ba}_{8} \mathrm{Al}_{x} \mathrm{Si}_{46-x}$. This is especially true for $\mathrm{Ba}_{8} \mathrm{Ga}_{x} \mathrm{Si}_{46-x}$ (see Figures $1 \mathrm{c}, 3 \mathrm{~b}, \mathrm{f}, \mathrm{j}$, and $\mathrm{S} 6$ ). On the other hand, in the case of $\mathrm{Ba}_{8} \mathrm{Ga}_{x} \mathrm{Ge}_{46-x}$ (see Figures $1 \mathrm{~b}, 3 \mathrm{a}, \mathrm{e}, \mathrm{i}$, and S5), it is evident that the Ga SOF at the $6 c$ and $16 i$ sites increases sharply as one approaches the transition temperature $T_{\text {trans }} \approx 300 \mathrm{~K}^{a}$. The same is true for $\mathrm{Ba}_{8} \mathrm{Al}_{x} \mathrm{Ge}_{46-x}$ (see Figures 1c, $3 c, g, k$, and S7) and $\mathrm{Ba}_{8} \mathrm{Al}_{x} \mathrm{Si}_{46-x}$ (see Figures 1d, 3d,h,l, and S8) at higher temperatures, namely, around 600-800 K. In addition, the SOFs for the Al-containing systems display abrupt shifts as the $\mathrm{Al}$ content increases; the occupation of the $6 c$ and $16 i$ sites increases sharply as the composition approaches $\mathrm{Ba}_{8} \mathrm{Al}_{16} \mathrm{Ge}_{30}$ and $\mathrm{Ba}_{8} \mathrm{Al}_{15} \mathrm{Si}_{30}$, respec- tively. It is interesting to note that peaks in the heat capacities are only observed at higher $\mathrm{Al}$ content. We assume that it is not a coincidence that the synthesis of $\mathrm{Ba}_{8} \mathrm{Al}_{x} \mathrm{Ge}_{46-x}$ with $x \geq$ $16^{53,54}$ and $\mathrm{Ba}_{8} \mathrm{Al}_{x} \mathrm{Si}_{46-x}$ with $x \geq 15^{31,55-59}$ has proved difficult. Instead, we suggest that not only the chemical ordering but also the order-disorder transition directly affects the stability of these compounds. Since the transition becomes less pronounced as the temperature increases and is almost absent above 750 and $850 \mathrm{~K}$ for $\mathrm{Ba}_{8} \mathrm{Al}_{x} \mathrm{Ge}_{46-x}$ and $\mathrm{Ba}_{8} \mathrm{Al}_{x} \mathrm{Si}_{46-x}$, respectively, it might, however, be possible to circumvent this problem by rapidly cooling the reaction mixture after the synthesis is complete, for instance via quenching.

The comparison between SOFs and heat capacities also reveals a plausible explanation for the fact that significantly lower transition temperatures are obtained (both experimentally and computationally) for $\mathrm{Ba}_{8} \mathrm{Ga}_{x} \mathrm{Ge}_{46-x}$ and $\mathrm{Ba}_{8} \mathrm{Ga}_{x} \mathrm{Si}_{46-x}$ compared to $\mathrm{Ba}_{8} \mathrm{Al}_{x} \mathrm{Ge}_{46-x}$ and $\mathrm{Ba}_{8} \mathrm{Al}_{x} \mathrm{Si}_{46-x}$. In particular, this is consistent with previous studies that have shown $\mathrm{Al}-\mathrm{Al}$ interactions to be less favorable than $\mathrm{Ga}-\mathrm{Ga}$ interactions, which is reflected by the larger pair effective cluster interactions (ECIs) for the former. ${ }^{39}$ Therefore, it seems likely that a higher temperature would be required to force the transition to a disordered state, which contains more $\mathrm{Al}-\mathrm{Al}$ bonds. As we have previously argued, ${ }^{39}$ this is the reason why $\mathrm{Al}$ atoms have a higher tendency to occupy a $6 c$ site, which is only connected to $24 k$ and $16 i$ sites.

Another particularly interesting result, which is most apparent in the case of $\mathrm{Ba}_{8} \mathrm{Al}_{x} \mathrm{Ge}_{46-x}$ (Figure $3 \mathrm{c}, \mathrm{g}, \mathrm{k}$ ) and $\mathrm{Ba}_{8} \mathrm{Al}_{x} \mathrm{Si}_{46-x}$ (Figure $3 \mathrm{~d}, \mathrm{~h}, \mathrm{l}$ ), is that three distinct regions appear when the SOFs and, less evidently, the heat capacities are mapped as functions of temperature and composition (Figure 1d,e). Specifically for $\mathrm{Ba}_{8} \mathrm{Al}_{x} \mathrm{Ge}_{46-x}\left(\mathrm{Ba}_{8} \mathrm{Al}_{x} \mathrm{Si}_{46-x}\right)$, 

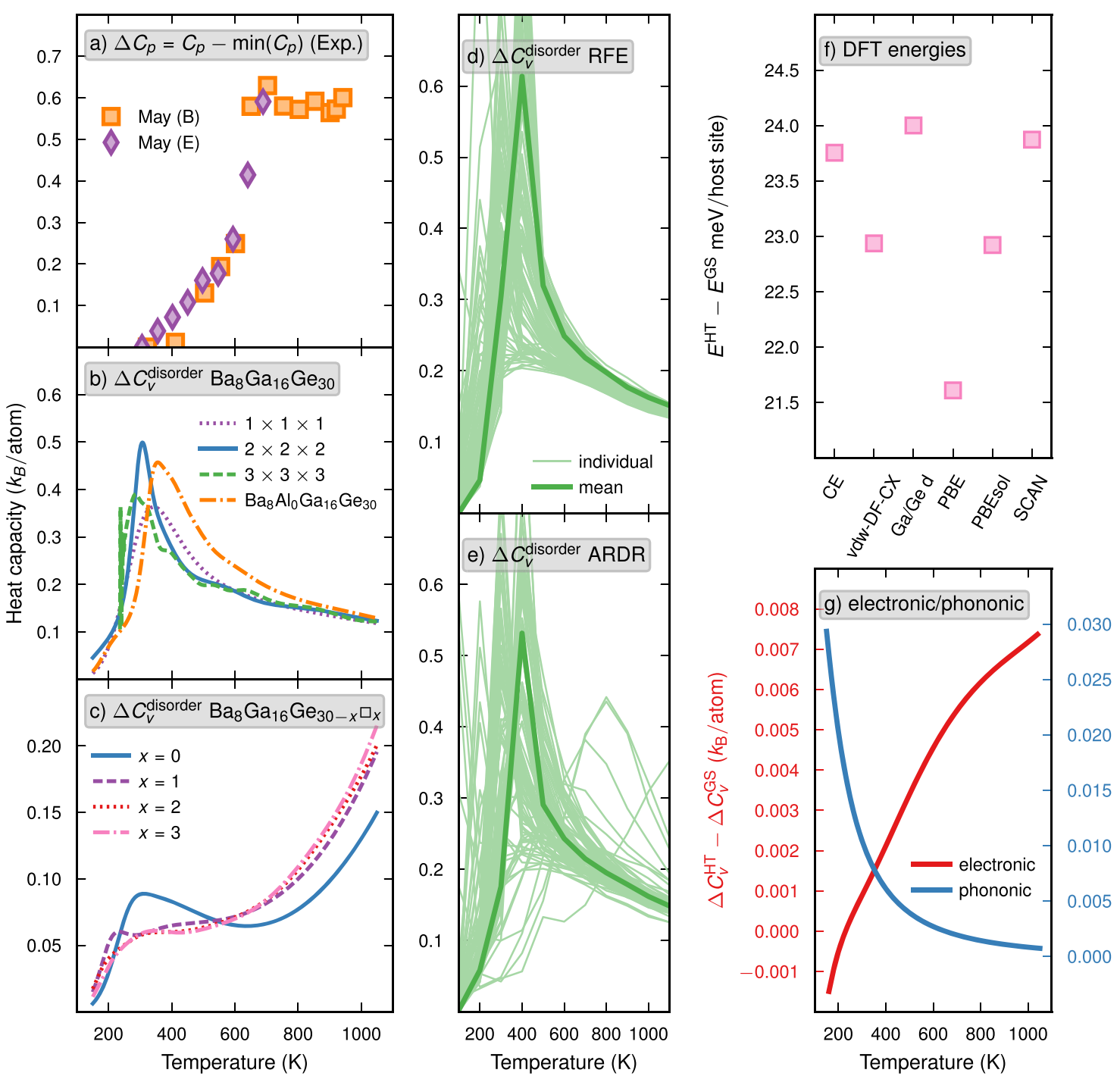

Figure 5. Investigation of the discrepancy between the experimentally determined and calculated transition temperatures for $\mathrm{Ba}_{8} \mathrm{Ga}_{x} \mathrm{Ge}_{46-x}$ (a) Experimental measurements by May et al. ${ }^{28}$ (b) Results from WL simulations for $1 \times 1 \times 1$ (dotted purple line), $2 \times 2 \times 2$ (solid blue line), and 3 $\times 3 \times 3$ (dashed green line) supercells as well as results obtained when using a ternary $\left(\mathrm{Ba}_{8} \mathrm{Al}_{x} \mathrm{Ga}_{y} \mathrm{Ge}_{46-x-y}\right) \mathrm{CE}$ (dashed-dotted orange line). (c) Data obtained by sampling a $\mathrm{Ba}_{8} \mathrm{Ga}_{x} \mathrm{Ge}_{46-x-y} \square_{y} \mathrm{CE}$ with no (solid blue line), a single (dashed purple line), two (dotted red line), and three (dashed-dotted pink line) vacancies $(\square)$. (d, e) Heat capacities extracted from MC simulations, at $700 \mathrm{~K}$, for ensembles of CEs (thin line) trained using either RFE with OLS (d) or ARDR (e); this also includes results for the average CE (thick line). (f) Difference between the energies for the ground state and the representative high-temperature $(1200 \mathrm{~K})$ configuration calculated using $\mathrm{PBE},{ }^{68} \mathrm{PBEsol},{ }^{69} \mathrm{SCAN},{ }^{70}$ and vdW-DF-cx ${ }^{71,72}$ functionals. Here, "Ga/Ge d" represents calculations, based on vdw-DF-CX, for Ga and Ge pseudopotentials that treat d orbitals as valence states. (g) Electronic (red) and phononic (blue) contributions to the heat capacity, the latter of which has been calculated based on the harmonic approximation.

there exists one area that corresponds to a well-ordered ground state with high $6 c / 16 i$ SOFs for $x \lesssim 16(x \lesssim 15)$ and $\lesssim 650 \mathrm{~K}$ and another with a lower order and $6 c / 16 i$ SOFs for $x \gtrsim 16(x$ $\gtrsim 15)$ and $T \lesssim 650 \mathrm{~K}(T \lesssim 650-850 \mathrm{~K})$ as well as a third disordered region at temperatures above $650 \mathrm{~K}(650-850 \mathrm{~K})$. Another key observation, which is the most evident for $\mathrm{Ba}_{8} \mathrm{Al}_{x} \mathrm{Si}_{46-x}$ (Figure $3 \mathrm{~d}, \mathrm{~h}, \mathrm{l}$ ), is that the transition line separating the low-temperature (ordered) region $(x \gtrsim 15$ and $T \lesssim 650-850 \mathrm{~K})$ and the high-temperature (disordered) region varies with composition from about $x \approx 15$ and $T \approx 650$ $\mathrm{K}$ to $x \approx 18$ and $T \approx 850 \mathrm{~K}$ in the same way as the ridge in the heat capacity (Figure 1e).

The data presented above demonstrate that the SOFs can serve as order parameters for the transition between the ordered and disordered states. For this reason, we have also compared the occupations for the ground-state and representative high-temperature $(1200 \mathrm{~K})$ configurations with experimental measurements from the literature (Figure 4). For $\mathrm{Ba}_{8} \mathrm{Ga}_{x} \mathrm{Ge}_{46-x}$ (Figure 4a,e) and $\mathrm{Ba}_{8} \mathrm{Ga}_{x} \mathrm{Si}_{46-x}$ (Figure $4 b, f)$, one observes better agreement with experimental SOF data for the high-temperature configurations. This indicates that the site occupations are frozen in before the ground state can be reached. This does not seem to be the case for $\mathrm{Ba}_{8} \mathrm{Al}_{x} \mathrm{Ge}_{46-x}$ (Figure 4c,g) and $\mathrm{Ba}_{8} \mathrm{Al}_{x} \mathrm{Si}_{46-x}$ (Figure 4d,h), for which the ground-state SOFs are closer to the experimental data. $^{b}$ This is consistent with higher transition temperatures, which allows for sufficient kinetic activation below the transition to reach the ordered (ground state) structure. This is fully consistent with the conclusions drawn above from the heat capacities from experiments and simulations. 
Analysis of Deviations. We have found semiquantitative agreement for the transition temperatures between the experiment and the simulation for $\mathrm{Ba}_{8} \mathrm{Al}_{x} \mathrm{Ge}_{46-x}$ and $\mathrm{Ba}_{8} \mathrm{Al}_{x} \mathrm{Si}_{46-x}$. For $\mathrm{Ba}_{8} \mathrm{Ga}_{x} \mathrm{Ge}_{46-x}$ and $\mathrm{Ba}_{8} \mathrm{Ga}_{x} \mathrm{Si}_{46-x}$, however, there is a notable underestimation. In this section, we therefore consider various possible sources, including both systematic errors related to the computations as well as contributions to the heat capacity from sources other than the chemical disorder. We focus on $\mathrm{Ba}_{8} \mathrm{Ga}_{16} \mathrm{Ge}_{30}$, instead of $\mathrm{Ba}_{8} \mathrm{Ga}_{16} \mathrm{Si}_{30}$, because the former has been more extensively studied.

Before proceeding, we emphasize that the energy differences involved are extremely small since these are continuous phase transitions. The extent to which the present models and the underlying DFT can capture this phenomenon is therefore already impressive.

First, we have compared the calculated heat capacities obtained from WL simulations based on $1 \times 1 \times 1,2 \times 2 \times 2$, and $3 \times 3 \times 3$ supercells when using $\mathrm{Ba}_{8} \mathrm{Ga}_{x} \mathrm{Ge}_{46-x}$ and, in the $2 \times 2 \times 2$ case, $\mathrm{Ba}_{8} \mathrm{Al}_{x} \mathrm{Ga}_{y} \mathrm{Ge}_{46-x-y}$ CEs with the experimental measurements by May et al. ${ }^{28}$ (Figure 5a,b). As expected, the use of a larger system shifts the transition to a lower temperature and thus leads to an even larger discrepancy.

Since $\mathrm{Ba}_{8} \mathrm{Ga}_{x} \mathrm{Ge}_{46-x}$ is known to contain vacancies, especially for off-stoichiometric compositions, ${ }^{25}$ we trained a $\mathrm{Ba}_{8} \mathrm{Ga}_{x} \mathrm{Ge}_{46-x-y} \square$. CE, where $\square$ represents a vacancy. The WL simulations using this model show that the peak not only appears at a slightly lower temperature but is also significantly dampened and almost disappears for $y \geq 2$ (Figure 5c).

We also checked the degree of variation with respect to the choice of fitting method as well as the set of training structures used when constructing the CEs. These tests included the analysis of heat capacities obtained by sampling ensembles of models that have been trained with recursive feature elimination (RFE) based on ordinary least squares (OLS) and automatic relevance detection regression (ARDR), respectively, at $700 \mathrm{~K}$ using $\mathrm{MC}$ simulations (Figure $5 \mathrm{~d}, \mathrm{e}$ ). Both methods yield comparable results but the variation in the peak positions predicted by the individual CEs can be as large as $200 \mathrm{~K}$. Even so, the results are clustered at around $400 \mathrm{~K}$, which is still $250 \mathrm{~K}$ lower than the experimentally determined temperature.

To check that the role of the underlying DFT calculations, we compared the energies obtained with $\mathrm{PBE},{ }^{68} \mathrm{PBEsol},{ }^{69}$ $\mathrm{SCAN}^{70}$ and vdW-DF-cx ${ }^{71,72}$ functionals (Figure $5 \mathrm{f}$ ). For the latter functional, we also carried out an extra set of calculations, using project augmented wave setups for $\mathrm{Ga}$ and $\mathrm{Ge}$ that include the d-electrons among the valence states. The estimates of the difference in energy between the representative high-temperature structure and the ground state vary by up to $2.5 \mathrm{meV}$ host site ${ }^{-1}$, which is small compared to the underestimation of the transition temperature $(250 \mathrm{~K} \approx 22$ $\mathrm{meV})$.

None of the possible sources of error discussed above are likely to be the sole cause of the discrepancy with respect to experiments. We therefore also calculated the electronic and phononic contributions to the heat capacity (Figure 5g). As reported previously, ${ }^{19}$ the former was determined by running Boltzmann transport theory (BTT) calculations for groundstate and high-temperature configurations, obtained with the help of a $\mathrm{Ba}_{8} \mathrm{Al}_{x} \mathrm{Ga}_{y} \mathrm{Ge}_{46-x-y} \mathrm{CE}$, using the BOLTzTRAP2 software. ${ }^{73} \mathrm{We}$ find that the electronic contribution for the high-temperature state is not only higher but also increases more quickly with temperature, which gives a difference of about $0.007 k_{\mathrm{B}}$ /atom at $1000 \mathrm{~K}$. This is, however, still an order of magnitude too small to have a notable impact on the total heat capacity. Based on the linear relationship between the jump in heat capacity and transition temperature observed for $\mathrm{Ba}_{8} \mathrm{Al}_{x} \mathrm{Ga}_{y} \mathrm{Ge}_{46-x-y}{ }^{19}$ we estimate that the corresponding temperature shift should be no higher than $10 \mathrm{~K}$.

A similar conclusion can be drawn with respect to the phononic contributions, which were calculated based on the harmonic approximation with the help of PHONOPY $^{50}$ using structures that were extracted in the same way as those used for the electronic transport calculations. In the present case, however, we employed a $\mathrm{Ba}_{8} \mathrm{Ga}_{x} \mathrm{Ge}_{46-x} \mathrm{CE}$ when running the MC simulations. The difference between the phononic heat capacity for the high-temperature configuration and the ground state is not only predicted to decrease with temperature but is in fact even smaller than the electronic contribution, with a maximum of about $0.001 k_{\mathrm{B}} /$ atom at $200 \mathrm{~K}$. This is consistent with higher-temperature phases commonly being vibrationally softer (due to energetically less favorable bonding configurations) than low-temperature phases (due to energetically more optimized bonding configurations), as discussed, e.g., in ref 74 .

As there appears to be no singular reason for the observed deviation, it is likely the consequence of a number of different factors, including the underlying DFT calculations (including the treatment of the d-states) and the electronic entropy.

\section{CONCLUSIONS}

We have conducted a comprehensive computational study of order-disorder transitions in the pseudobinary clathrates $\mathrm{Ba}_{8} \mathrm{Ga}_{x} \mathrm{Ge}_{46-x}, \mathrm{Ba}_{8} \mathrm{Ga}_{x} \mathrm{Si}_{46-x}, \mathrm{Ba}_{8} \mathrm{Al}_{x} \mathrm{Ge}_{46-x}$, and $\mathrm{Ba}_{8} \mathrm{Al}_{x} \mathrm{Si}_{46-x}$, using alloy CEs and WL simulations. All four systems exhibit order-disorder transitions across the composition range that is the most relevant from a practical perspective $(14 \leq x \leq 18)$. We have found evidence in the literature that this phenomenon is common among type-I clathrates, e.g., in $\mathrm{Ba}_{8} \mathrm{Al}_{x} \mathrm{Ga}_{y} \mathrm{Ge}_{46-x-y}{ }^{19} \mathrm{Ba}_{8-y} \mathrm{Eu}_{y} \mathrm{Al}_{x} \mathrm{Si}_{46-x},{ }^{30} \mathrm{Ba}_{8} \mathrm{Ga}_{x} \mathrm{In}_{y} \mathrm{Ge}_{46-x-y}{ }^{35}$ $\mathrm{Ba}_{8} \mathrm{~B}_{x} \mathrm{Al}_{y} \mathrm{Si}_{46-x-y},{ }^{36}$ and $\mathrm{Ba}_{8-y} \mathrm{Sr}_{y} \mathrm{Al}_{x} \mathrm{Si}_{46-x}{ }^{37}$ as well as $\mathrm{Rb}_{8} \mathrm{Sn}_{44} \square_{2}$ and $\mathrm{Cs}_{8} \mathrm{Sn}_{44} \square_{2} \cdot{ }^{17,18}$

Our previous study of $\mathrm{Ba}_{8} \mathrm{Al}_{x} \mathrm{Ga}_{y} \mathrm{Ge}_{46-x-y}{ }^{19}$ has demonstrated that order-disorder transitions can lead to key changes in the band structure, which, in turn, affect the electronic transport properties. It is therefore clear that the orderdisorder transition is of interest also from a practical perspective. This can make it worthwhile to revisit some of these systems, as it is not uncommon for such transitions to be neglected or overlooked, for instance when estimating thermal transport properties. ${ }^{1}$ Hopefully the present study can serve as a guide for the exploration of similar phenomena in other pseudobinary and ternary alloys, in which two chemical species occupy the same sublattice, as well as the type of information that can be gained from such investigations.

While for the Al-containing systems, we have found good agreement with the experiment, we observed a notable underestimation for the Ga-containing clathrates. We have considered several possible reasons but it appears that the error has multiple sources, which can warrant closer inspection. Nonetheless, given the very small energy differences that are involved in such a continuous transition, the ability of both the underlying DFT calculations and the CE models to capture this phenomenon is impressive. 


\section{ASSOCIATED CONTENT}

\section{(s) Supporting Information}

The Supporting Information is available free of charge at https://pubs.acs.org/doi/10.1021/acs.jpcc.1c06638.

Learning curves; effective cluster interactions; predictive errors; heat capacity for different system sizes; heat capacity and SOFs for $\mathrm{Ba}_{8} \mathrm{Ga}_{x} \mathrm{Ge}_{46-x}, \mathrm{Ba}_{8} \mathrm{Ga}_{x} \mathrm{Si}_{46-x}$, $\mathrm{Ba}_{8} \mathrm{Al}_{x} \mathrm{Ge}_{46-x}$, and $\mathrm{Ba}_{8} \mathrm{Al}_{x} \mathrm{Si}_{46-x}$; experimental transition temperatures; electronic structure calculations; cluster expansion construction; Monte Carlo simulations; and phononic heat capacity (PDF)

\section{AUTHOR INFORMATION}

\section{Corresponding Author}

Paul Erhart - Department of Physics, Chalmers University of Technology, SE-41296 Gothenburg, Sweden; (1) orcid.org/ 0000-0002-2516-6061; Email: erhart@chalmers.se

\section{Authors \\ Joakim Brorsson - Department of Chemistry and Chemical Engineering, Chalmers University of Technology, SE-412 96 Gothenburg, Sweden \\ Anders E. C. Palmqvist - Department of Chemistry and Chemical Engineering, Chalmers University of Technology, SE-412 96 Gothenburg, Sweden; (1) orcid.org/0000-0002- $7579-3936$}

Complete contact information is available at:

https://pubs.acs.org/10.1021/acs.jpcc.1c06638

\section{Notes}

The authors declare no competing financial interest.

\section{ACKNOWLEDGMENTS}

The authors gratefully acknowledge Yifei Zhang for his participation in many helpful discussions. This work was funded by the Knut and Alice Wallenberg Foundation (2014.0226) and the Swedish Research Council (2018-06482 and 2020-04935) as well as the Danish Council for Strategic Research via the Programme Commission on Sustainable Energy and Environment through sponsoring of the project "CTEC-Center for Thermoelectric Energy Conversion" (Project No. 1305-00002B). The computations were enabled by resources provided by the Swedish National Infrastructure for Computing (SNIC) at NSC, C3SE, and PDC partially funded by the Swedish Research Council through Grant Agreement No. 2018-05973.

\section{ADDITIONAL NOTES}

${ }^{a}$ We note that the variations of the SOFs in refs 38,39 are much smoother. This is due to the fact that these studies employed direct MC simulations, for which critical slowdown makes it computationally extremely demanding to properly sample the system near the transition, motivating the use of the WL technique. ${ }^{47}$

${ }^{b}$ We note that some of the experimental data correspond to compositions with low $\mathrm{Al}$ content. They are therefore likely to contain vacancies, which complicates the comparison between the simulation and the experiment.

\section{REFERENCES}

(1) Agne, M. T.; Voorhees, P. W.; Snyder, G. J. Phase Transformation Contributions to Heat Capacity and Impact on
Thermal Diffusivity, Thermal Conductivity, and Thermoelectric Performance. Adv. Mater. 2019, 31, No. 1902980.

(2) Zhang, J.; Song, L.; Iversen, B. B. Insights into the design of thermoelectric $\mathrm{Mg}_{3} \mathrm{Sb}_{2}$ and its analogs by combining theory and experiment. npj Comput. Mater. 2019, 5, No. 76.

(3) Wu, Y.; Litvinchuk, A. P.; Toberer, E. S.; Snyder, G. J.; Newman, N.; Fischer, A.; Scheidt, E.-W.; Scherer, W.; Häussermann, U. Thermoelectric properties of $\mathrm{Zn}_{5} \mathrm{Sb}_{4} \mathrm{In}_{2-\delta}(\delta=0.15)$. J. Appl. Phys. 2012, 111, No. 123712.

(4) Pomrehn, G. S.; Toberer, E. S.; Snyder, G. J.; van de Walle, A. Entropic stabilization and retrograde solubility in $\mathrm{Zn}_{4} \mathrm{Sb}_{3}$. Phys. Rev. $B$ 2011, 83, No. 094106.

(5) Sommer, S.; Bøjesen, E. D.; Lock, N.; Kasai, H.; Skibsted, J.; Nishibori, E.; Iversen, B. B. Probing the validity of the spinel inversion model: a combined SPXRD, PDF, EXAFS and NMR study of $\mathrm{ZnAl}_{2} \mathrm{O}_{4}$. Dalton Trans. 2020, 49, 13449-13461.

(6) Li, B.; Wang, H.; Kawakita, Y.; Zhang, Q.; Feygenson, M.; Yu, H. L.; Wu, D.; Ohara, K.; Kikuchi, T.; Shibata, K.; et al. Liquid-like thermal conduction in intercalated layered crystalline solids. Nat. Mater. 2018, 17, 226-230.

(7) Heep, B. K.; Weldert, K. S.; Krysiak, Y.; Day, T. W.; Zeier, W. G.; Kolb, U.; Snyder, G. J.; Tremel, W. High Electron Mobility and Disorder Induced by Silver Ion Migration Lead to Good Thermoelectric Performance in the Argyrodite $\mathrm{Ag}_{8} \mathrm{SiSe}_{6}$. Chem. Mater. 2017, 29, 4833-4839.

(8) Pöhls, J.-H.; Luo, Z.; Aydemir, U.; Sun, J.-P.; Hao, S.; He, J.; Hill, I. G.; Hautier, G.; Jain, A.; Zeng, X.; et al. First-principles calculations and experimental studies of $\mathrm{XYZ}_{2}$ thermoelectric compounds: detailed analysis of van der Waals interactions. J. Mater. Chem. A 2018, 6, 19502-19519.

(9) Roth, N.; Iversen, B. B. Solving the disordered structure of $\beta$ $\mathrm{Cu}_{2-x} \mathrm{Se}$ using the three-dimensional difference pair distribution function. Acta Crystallogr., Sect. A 2019, 75, 465-473.

(10) Brown, D. R.; Heijl, R.; Borup, K. A.; Iversen, B. B.; Palmqvist, A.; Snyder, G. J. Relating phase transition heat capacity to thermal conductivity and effusivity in $\mathrm{Cu}_{2} \mathrm{Se}$. Phys. Status Solidi $R R L$ 2016, 10 , 618-621.

(11) Weldert, K. S.; Zeier, W. G.; Day, T. W.; Panthöfer, M.; Snyder, G. J.; Tremel, W. Thermoelectric Transport in $\mathrm{Cu}_{7} \mathrm{PSe}_{6}$ with High Copper Ionic Mobility. J. Am. Chem. Soc. 2014, 136, 12035-12040.

(12) Reissig, F.; Heep, B.; Panthöfer, M.; Wood, M.; Anand, S.; Snyder, G. J.; Tremel, W. Effect of anion substitution on the structural and transport properties of argyrodites $\mathrm{Cu}_{7} \mathrm{PSe}_{6-x} \mathrm{~S}_{x}$. Dalton Trans. 2019, 48, 15822-15829.

(13) Sist, M.; Kasai, H.; Hedegaard, E. M. J.; Iversen, B. B. Role of vacancies in the high-temperature pseudodisplacive phase transition in GeTe. Phys. Rev. B 2018, 97, No. 094116.

(14) Xia, K.; Nan, P.; Tan, S.; Wang, Y.; Ge, B.; Zhang, W.; Anand, S.; Zhao, X.; Snyder, G. J.; Zhu, T. Short-range order in defective halfHeusler thermoelectric crystals. Energy Environ. Sci. 2019, 12, 15681574.

(15) Zeier, W. G.; Anand, S.; Huang, L.; He, R.; Zhang, H.; Ren, Z.; Wolverton, C.; Snyder, G. J. Using the 18-Electron Rule To Understand the Nominal 19-Electron Half-Heusler $\mathrm{NbCoSb}$ with $\mathrm{Nb}$ Vacancies. Chem. Mater. 2017, 29, 1210-1217.

(16) Isaacs, E. B.; Wolverton, C. Electronic Structure and Phase Stability of $\mathrm{Yb}$-Filled $\mathrm{CoSb}_{3}$ Skutterudite Thermoelectrics from FirstPrinciples. Chem. Mater. 2019, 31, 6154-6162.

(17) Christensen, S.; Bjerg, L.; Kaltzoglou, A.; Juranyi, F.; Fässler, T.; Unruh, T.; Christensen, M. Guest host interaction and low energy host structure dynamics in tin clathrates. J. Appl. Phys. 2013, 113, No. 084902.

(18) Kaltzoglou, A.; Fössler, T.; Christensen, M.; Johnsen, S.; Iversen, B.; Presniakov, I.; Sobolev, A.; Shevelkov, A. Effects of the order-disorder phase transition on the physical properties of $\mathrm{A}_{8} \mathrm{Sn}_{44} \square_{2}$ (A = Rb, Cs). J. Mater. Chem. 2008, 18, 5630-5637.

(19) Brorsson, J.; Zhang, Y.; Palmqvist, A. E. C.; Erhart, P. OrderDisorder Transition in Inorganic Clathrates Controls Electrical Transport Properties. Chem. Mater. 2021, 33, 4500. 
(20) Christensen, M.; Johnsen, S.; Iversen, B. B. Thermoelectric clathrates of type I. Dalton Trans. 2010, 39, 978-992.

(21) Takabatake, T.; Suekuni, K.; Nakayama, T.; Kaneshita, E. Phonon-glass electron-crystal thermoelectric clathrates: Experiments and theory. Rev. Mod. Phys. 2014, 86, 669-716.

(22) Dolyniuk, J.-A.; Owens-Baird, B.; Wang, J.; Zaikina, J. V.; Kovnir, K. Clathrate thermoelectrics. Mater. Sci. Eng. R 2016, 108, 146.

(23) Kuznetsov, V. L.; Kuznetsova, L. A.; Kaliazin, A. E.; Rowe, D. M. Preparation and thermoelectric properties of $A_{8}^{\mathrm{II}} B_{16}^{\mathrm{III}} B_{30}^{\mathrm{IV}}$ clathrate compounds. J. Appl. Phys. 2000, 87, 7871-7875.

(24) Saramat, A.; Svensson, G.; Palmqvist, A. E. C.; Stiewe, C.; Mueller, E.; Platzek, D.; Williams, S. G. K.; Rowe, D. M.; Bryan, J. D.; Stucky, G. D. Large thermoelectric figure of merit at high temperature in Czochralski-grown clathrate $\mathrm{Ba}_{8} \mathrm{Ga}_{16} \mathrm{Ge}_{30}$. J. Appl. Phys. 2006, 99, No. 023708 .

(25) Okamoto, N. L.; Kishida, K.; Tanaka, K.; Inui, H. Crystal structure and thermoelectric properties of type-I clathrate compounds in the Ba-Ga-Ge system. J. Appl. Phys. 2006, 100, No. 073504.

(26) Toberer, E. S.; Christensen, M.; Iversen, B. B.; Snyder, G. J. High temperature thermoelectric efficiency in $\mathrm{Ba}_{8} \mathrm{Ga}_{16} \mathrm{Ge}_{30}$. Phys. Rev. B 2008, 77, No. 075203.

(27) Martin, J.; Wang, H.; Nolas, G. S. Optimization of the thermoelectric properties of $\mathrm{Ba}_{8} \mathrm{Ga}_{16} \mathrm{Ge}_{30}$. Appl. Phys. Lett. 2008, 92, No. 222110.

(28) May, A. F.; Toberer, E. S.; Saramat, A.; Snyder, G. J. Characterization and analysis of thermoelectric transport in $n$-type $\mathrm{Ba}_{8} \mathrm{Ga}_{x} \mathrm{Ge}_{30-x}$. Phys. Rev. B 2009, 80, No. 125205.

(29) Reardon, H.; Blichfeld, A. B.; Kasai, H.; Yin, H.; Bojesen, E. D.; Iversen, B. B. Revealing the slow decomposition kinetics of type-I clathrate $\mathrm{Ba}_{8} \mathrm{Ga}_{16} \mathrm{Ge}_{30}$. Phys. Chem. Chem. Phys. 2017, 19, 1573415744 .

(30) Condron, C. L.; Kauzlarich, S. M.; Gascoin, F.; Snyder, G. J. Thermoelectric Properties and Microstructure of $\mathrm{Ba}_{8} \mathrm{Al}_{14} \mathrm{Si}_{31}$ and EuBa $\mathrm{Al}_{13} \mathrm{Si}_{33}$. Chem. Mater. 2006, 18, 4939-4945.

(31) Tsujii, N.; Roudebush, J. H.; Zevalkink, A.; Cox-Uvarov, C. A.; Snyder, G. J.; Kauzlarich, S. M. Phase stability and chemical composition dependence of the thermoelectric properties of the type-I clathrate $\mathrm{Ba}_{8} \mathrm{Al}_{x} \mathrm{Si}_{46-x},(8 \leqslant x \leqslant 15)$. J. Solid State Chem. 2011, 184, 1293-1303.

(32) Bentien, A.; Nishibori, E.; Paschen, S.; Iversen, B. B. Crystal structures, atomic vibration, and disorder of the type-I thermoelectric clathrates $\mathrm{Ba}_{8} \mathrm{Ga}_{16} \mathrm{Si}_{30}, \mathrm{Ba}_{8} \mathrm{Ga}_{16} \mathrm{Ge}_{30}, \mathrm{Ba}_{8} \mathrm{In}_{16} \mathrm{Ge}_{30}$, and $\mathrm{Sr}_{8} \mathrm{Ga}_{16} \mathrm{Ge}_{30}$. Phys. Rev. B 2005, 71, No. 144107.

(33) Bentien, A.; Iversen, B.; Bryan, J.; Stucky, G.; Palmqvist, A.; Schultz, A.; Henning, R. Maximum entropy method analysis of thermal motion and disorder in thermoelectric clathrate $\mathrm{Ba}_{8} \mathrm{Ga}_{16} \mathrm{Si}_{30}$. J. Appl. Phys. 2002, 91, 5694-5699.

(34) Anno, H.; Yamada, H.; Nakabayashi, T.; Hokazono, M.; Shirataki, R. Gallium composition dependence of crystallographic and thermoelectric properties in polycrystalline type-I $\mathrm{Ba}_{8} \mathrm{Ga}_{x} \mathrm{Si}_{46-x}$ (nominal $x=14-18$ ) clathrates prepared by combining arc melting and spark plasma sintering methods. J. Solid State Chem. 2012, 193, 94-104.

(35) Okamoto, N. L.; Kishida, K.; Tanaka, K.; Inui, H. Effect of In additions on the thermoelectric properties of the type-I clathrate compound $\mathrm{Ba}_{8} \mathrm{Ga}_{16} \mathrm{Ge}_{30}$. J. Appl. Phys. 2007, 101, No. 113525 .

(36) Condron, C. L.; Kauzlarich, C.; Ikeda, S.; Snyder, T. J.; Haarmann, G.; Jeglic, F. Synthesis, Structure, and High-Temperature Thermoelectric Properties of Boron-Doped $\mathrm{Ba}_{8} \mathrm{Al}_{14} \mathrm{Si}_{31}$ Clathrate I Phases. Inorg. Chem. 2008, 47, 8204-8212.

(37) Roudebush, J.; Toberer, E.; Hope, H.; Jeffrey Snyder, G.; Kauzlarich, S. Crystal structure, characterization and thermoelectric properties of the type-I clathrate $\mathrm{Ba}_{8-y} \mathrm{Sr}_{y} \mathrm{Al}_{14} \mathrm{Si}_{32}(0.6 \leqslant y \leqslant 1.3)$ prepared by aluminum flux. J. Solid State Chem. 2011, 184, 11761185

(38) Ångqvist, M.; Lindroth, D. O.; Erhart, P. Optimization of the thermoelectric power factor: Coupling between chemical order and transport properties. Chem. Mater. 2016, 28, 6877.
(39) Ångqvist, M.; Erhart, P. Understanding chemical ordering in intermetallic clathrates from atomic scale simulations. Chem. Mater. 2017, 29, 7554 .

(40) Troppenz, M.; Rigamonti, S.; Draxl, C. Predicting GroundState Configurations and Electronic Properties of the Thermoelectric Clathrates $\mathrm{Ba}_{8} \mathrm{Al}_{x} \mathrm{Si}_{46-x}$ and $\mathrm{Sr}_{8} \mathrm{Al}_{x} \mathrm{Si}_{46-x}$. Chem. Mater. 2017, 29, 2414-2424.

(41) Troppenz, M.; Rigamonti, S.; Sofo, J.; Draxl, C. Partial OrderDisorder Transition Driving Closure of Band Gap: Example of Thermoelectric Clathrates, 2020. arXiv:2009.11137, https://arxiv. org/abs/2009.11137v1.

(42) Ångqvist, M.; Muñoz, W. A.; Rahm, J. M.; Fransson, E.; Durniak, C.; Rozyczko, P.; Rod, T. H.; Erhart, P. ICET-A Python Library for Constructing and Sampling Alloy Cluster Expansions. Adv. Theory Simul. 2019, 2, No. 1900015.

(43) Blöchl, P. E. Projector augmented-wave method. Phys. Rev. B 1994, 50, 17953-17979.

(44) Kresse, G.; Joubert, D. From ultrasoft pseudopotentials to the projector augmented-wave method. Phys. Rev. B 1999, 59, 17581775.

(45) Kresse, G.; Furthmüller, J. Efficient iterative schemes for $a b$ initio total-energy calculations using a plane-wave basis set. Phys. Rev. B 1996, 54, No. 11169.

(46) Fransson, E.; Eriksson, F.; Erhart, P. Efficient construction of linear models in materials modeling and applications to force constant expansions. npj Comput. Mater. 2020, 6, No. 135.

(47) Wang, F.; Landau, D. P. Efficient, Multiple-Range Random Walk Algorithm to Calculate the Density of States. Phys. Rev. Lett. 2001, 86, 2050-2053.

(48) van de Walle, A.; Tiwary, P.; de Jong, D. L. O. M.; Asta, M.; Dick, A.; Shin, D.; Wang, Y.; Chen, L.-Q.; Liu, Z.-K. Efficient stochastic generation of special quasirandom structures. Calphad 2013, 42, No. 13.

(49) Larsen, P. M.; Jacobsen, K. W.; Schiøtz, J. Rich Ground-State Chemical Ordering in Nanoparticles: Exact Solution of a Model for Ag-Au Clusters. Phys. Rev. Lett. 2018, 120, No. 256101.

(50) Togo, A.; Tanaka, I. First Principles Phonon Calculations in Materials Science. Scr. Mater. 2015, 108, 1-5.

(51) Eriksson, F.; Fransson, E.; Erhart, P. The Hiphive Package for the Extraction of High-Order Force Constants by Machine Learning. Adv. Theory Simul. 2019, 2, No. 1800184.

(52) Pelton, A. D. Phase Diagrams and Thermodynamic Modeling of Solutions; Elsevier: Amsterdam, Netherlands, 2019.

(53) Christensen, M.; Iversen, B. B. Host Structure Engineering in Thermoelectric Clathrates. Chem. Mater. 2007, 19, 4896-4905.

(54) Rodriguez, S. Y.; Saribaev, L.; Ross, J. H. Zintl behavior and vacancy formation in type-I Ba-Al-Ge clathrates. Phys. Rev. B 2010, 82, No. 064111.

(55) Mugita, N.; Nakakohara, Y.; Teranishi, R.; Munetoh, S. Single crystallization of Ba8AlxSi46-x clathrate for improvement of thermoelectric properties. J. Mater. Res. 2011, 26, 1857-1860.

(56) Nakakohara, Y.; Mugita, N.; Nagatomo, Y.; Saisho, M.; Motooka, T.; Teranishi, R.; Munetoh, S. Single crystallization of Ba8AlxSi46-x clathrate by using the flux Czochralski method. MRS Proc. 2011, 1325, No. 306.

(57) Nagatomo, Y.; Mugita, N.; Nakakohara, Y.; Saisho, M.; Tajiri, M.; Teranishi, R.; Munetoh, S. Thermoelectric properties of single crystalline $\mathrm{Ba}_{8} \mathrm{Al}_{x} \mathrm{Si}_{46-x}$ clathrate by using flux Czochralski method. J. Phys.: Conf. Ser. 2012, 379, No. 012008.

(58) Roudebush, J. H.; de la Cruz, C.; Chakoumakos, B. C.; Kauzlarich, S. M. Neutron Diffraction Study of the Type I Clathrate $\mathrm{Ba}_{8} \mathrm{Al}_{x} \mathrm{Si}_{46-x}$ : Site Occupancies, Cage Volumes, and the Interaction between the Guest and the Host Framework. Inorg. Chem. 2012, 51, $1805-1812$

(59) Anno, H.; Hokazono, M.; Shirataki, R.; Nagami, Y. Crystallographic, Thermoelectric, and Mechanical Properties of Polycrystalline $\mathrm{Ba}_{8} \mathrm{Al}_{x} \mathrm{Si}_{46-x}$ Clathrates. J. Electron. Mater. 2013, 42, 2326-2336.

(60) Christensen, M.; Lock, N.; Overgaardk, J.; Iversen, B. B. Crystal Structures of Thermoelectric n- and p-type Ba8Ga16Ge30 Studied by 
Single Crystal, Multitemperature, Neutron Diffraction, Conventional X-ray Diffraction and Resonant Synchrotron X-ray Diffraction. J. Am. Chem. Soc. 2006, 128, 15657-15665.

(61) Eisenmann, B.; Schäfer, H.; Zagler, R. Die Verbindungen $\mathrm{AI}_{8}^{I} \mathrm{~B}_{16}^{I I I} \mathrm{~B}_{30}^{I V} \quad\left(\mathrm{~A}^{I I} \equiv \mathrm{Sr}, \mathrm{Ba} ; \mathrm{B}^{I I I} \equiv \mathrm{Al}, \mathrm{Ga} ; \mathrm{B}^{I V} \equiv \mathrm{Si}, \mathrm{Ge}, \mathrm{Sn}\right)$ und ihre Käfigstrukturen. J. Less Common Met. 1986, 118, 43-55.

(62) Christensen, M.; Snyder, G.; Iversen, B. In 25th International Conference on Thermoelectrics, IEEE: New York, NY, 2006; pp 40-43.

(63) Qiu, L.; Swainson, I. P.; Nolas, G. S.; White, M. A. Structure, thermal, and transport properties of the clathrates $\mathrm{Sr}_{8} \mathrm{Zn}_{8} \mathrm{Ge}_{38}$, $\mathrm{Sr}_{8} \mathrm{Ga}_{16} \mathrm{Ge}_{30}$, and $\mathrm{Ba}_{8} \mathrm{Ga}_{16} \mathrm{Si}_{30}$. Phys. Rev. B 2004, 70, No. 035208.

(64) Bobnar, M.; Böhme, B.; Wedel, M.; Burkhardt, U.; Ormeci, A.; Prots, Y.; Drathen, C.; Liang, Y.; Nguyen, H. D.; Baitinger, M.; et al. Distribution of $\mathrm{Al}$ atoms in the clathrate-I phase $\mathrm{Ba}_{8} \mathrm{Al}_{x} \mathrm{Si}_{46-x}$ at $x=$ 6.9. Dalton Trans. 2015, 44, 12680-12687.

(65) Christensen, M.; Johnsen, S.; Søndergaard, M.; Overgaard, J.; Birkedal, H.; Iversen, B. B. Fast Preparation and Characterization of Quarternary Thermoelectric Clathrates. Chem. Mater. 2009, 21, 122127.

(66) Puspita, W. R.; Takeya, H.; Mochiku, T.; Ishikawa, Y.; Lee, S.; Torii, S.; Hagihala, M.; Kamiyama, T. In Structural Study of Thermoelectric Clathrate $\mathrm{Ba}_{8} A l_{16-x} G a_{x} G e_{30}$, 2nd International Conference on Applied Engineering (ICAE), New York, NY, 2019; pp 1-5.

(67) Nataraj, D.; Nagao, J. Structure and Raman scattering study on Ba8GaxSi46-x $(x=10$ and 16) type I clathrates. J. Solid State Chem. 2004, 177, 1905-1911.

(68) Perdew, J. P.; Burke, K.; Ernzerhof, M. Generalized Gradient Approximation Made Simple. Phys. Rev. Lett. 1996, 77, 3865-3868.

(69) Perdew, J. P.; Ruzsinszky, A.; Csonka, G. I.; Vydrov, O. A.; Scuseria, G. E.; Constantin, L. A.; Zhou, X.; Burke, K. Restoring the Density-Gradient Expansion for Exchange in Solids and Surfaces. Phys. Rev. Lett. 2008, 100, No. 136406.

(70) Sun, J.; Ruzsinszky, A.; Perdew, J. P. Strongly Constrained and Appropriately Normed Semilocal Density Functional. Phys. Rev. Lett. 2015, 115, No. 036402.

(71) Berland, K.; Cooper, V. R.; Lee, K.; Schröder, E.; Thonhauser, T.; Hyldgaard, P.; Lundqvist, B. I. Van Der Waals Forces in Density Functional Theory: A Review of the vdW-DF Method. Rep. Prog. Phys. 2015, 78, No. 066501.

(72) Berland, K.; Hyldgaard, P. Exchange functional that tests the robustness of the plasmon description of the van der Waals density functional. Phys. Rev. B 2014, 89, No. 035412.

(73) Madsen, G. K.; Carrete, J.; Verstraete, M. J. BoltzTraP2, a program for interpolating band structures and calculating semiclassical transport coefficients. Comput. Phys. Commun. 2018, 231, $140-145$.

(74) Gren, M.; Fransson, E.; Ångqvist, M.; Erhart, P.; Wahnström, G. Modeling of vibrational and configurational degrees of freedom in hexagonal and cubic tungsten carbide at high temperatures. Phys. Rev. Mater. 2021, 5, No. 033804. 